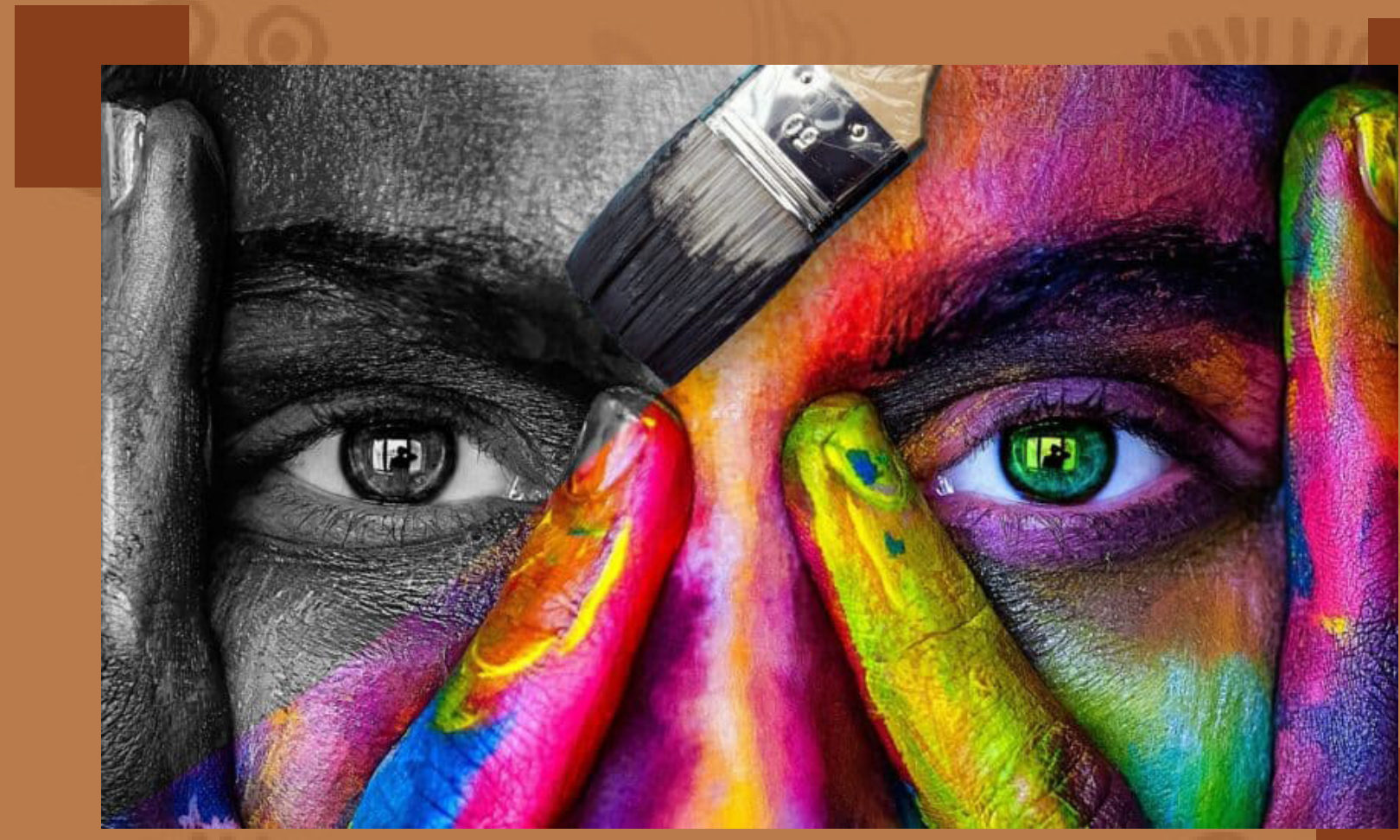

\title{
La implicancia subjetiva y la reflexividad en la construcción de conocimiento antropológico
}

El camino de la antropología 


\section{La implicancia subjetiva y la reflexividad en la construcción de conocimiento antropológico}

It is implied by subjective and reflexivity in the contruction of anthropological knowledge

María Cecilia Telleria

Originaria de Argentina. Antropóloga, Maestranda en Estudios Culturales

Adscripta en Metodología y Técnicas de Investigación IIII (Orientación Sociocultural)

Universidad Nacional de Rosario, Argentina

ID Orcid: https://orcid.org/0000-0002-1971-5968

telleriacecilia@gmail.com

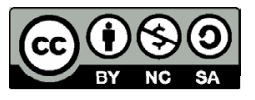

Copyright $\odot 2021$ UNAN-Managua Todos los Derechos Reservados.

\section{Resumen}

Se analiza la problemática de la implicancia subjetiva y la reflexividad en el trabajo de campo antropológico. El artículo comienza exponiendo sobre el trabajo de campo antropológico en la construcción de conocimiento científico, algunas experiencias y reflexiones particulares sobre este exponiendo los rasgos y las condiciones de producción de dicho conocimiento. Se considera que la construcción de conocimiento mediante trabajo de campo, implica la subjetividad e implicancia del/a investigador/ra, resultando pertinente explicitar para que posibilite y no obstaculice la construcción de conocimiento social.

Palabras claves: trabajo de campo, Antropología, implicancia subjetiva, reflexividad, conocimiento.

\section{Abstract}

The problem of subjective implication and reflexivity in anthropological fieldwork is analyzed. The article begins by exposing on the anthropological fieldwork in the construction of scientific knowledge, some experiences and particular reflections on this, exposing the features and conditions of production of said knowledge. It is considered that the construction of knowledge through field work implies the subjectivity and implication of the researcher, making it pertinent to make it explicit so that it enables and does not hinder the construction of social knowledge.

Keywords: field work, Anthropology, subjective implication, reflexivity, knowledge. 


\section{Introducción}

\section{Sobre el trabajo de campo antropológico en la construcción de conocimiento científico}

Desde los orígenes de la Antropología, el "otro" como objeto de estudio era abordado desde parámetros culturales diferentes a los del investigador, pretendiendo la construcción de objetividad y veracidad. La noción de objetividad se basaba en la recolección de datos cuantificables y demostrables, siguiendo el modelo científico de las Ciencias Naturales, hegemónico del siglo XIX. La búsqueda de status científico por parte de la Antropología, llegó con las corrientes funcionalistas y relativistas, principalmente de etnógrafos como B. Malinowski, quien ofrecía una metodología de trabajo de campo para captar los "imponderables de la vida real y los comportamientos típicos", el "punto de vista del nativo" y la estructura social, que, sumado a la elaboración teórica, generaría un análisis científico, por lo tanto objetivo de los "otros" estudiados.

En las investigaciones socioculturales no se ofrece el punto de vista del "nativo", de ese "otro", sin mediación alguna de la propia subjetividad del investigador/ra. El análisis que se realiza tampoco se produce de forma alguna bajo la neutralidad valorativa que sostienen las corrientes de corte positivista en Ciencias Sociales. En este sentido, como sujetos que forman parte de la misma sociedad que esos "otros" cuyo universo pretenden indagar, los investigadores/ras se encuentran condicionados por su propia interpretación del mundo social, por su bagaje teórico y de supuestos a priori, así como también por sus estados emocionales o psicológicos que atraviesan a lo largo del proceso de investigación. Partiendo de este enfoque, se considera que el trabajo de campo es "todo aquello con lo que se relaciona el investigador, pues el campo es una cierta conjunción entre un ámbito físico, actores y actividades." (Guber, 2004: p. 83-84)

Las relaciones que se entablan en el trabajo de campo y el registro que se toma del mismo, están mediadas por la subjetividad del investigador/ra, como también por problemas éticos: "el sentirse extraño en la localidad, sentirse intruso, reportero, espía, académico o evaluador." (Rockwell: 2011, p. 53). En el transcurso del mismo, se van definiendo compromisos y espacios de acción, que alivian esa carga culposa, ya que: "no está ausente lo político de la construcción de conocimiento ni tampoco está ausente la producción de conocimiento de las prácticas políticas." (2011, p. 96) Estas prácticas en el campo, sumado a lo teórico y al sentido común, convergen en lo que se ha llamado "reflexividad", la cual: "es el proceso de interacción, diferenciación y reciprocidad entre la reflexividad del sujeto cognoscente y la de los actores/objetos de investigación." (Guber: 2004, p. 87)

En el trabajo de campo convergen tres reflexividades: la del investigador en tanto perteneciente a una sociedad; la del investigador en tanto investigador y las reflexividades del grupo u organización social de estudio. Por lo que es preciso cierta "vigilancia" entre estas reflexividades para poder describir y comprender la cotidianeidad que se vivencia en el campo, para alcanzar su objetivación. En esta línea, resulta significativa la calificación de Elias (1990) para designar la vieja dicotomía "objetividad-subjetividad" como "compromiso y distanciamiento", debido a que en todo conocimiento no hay ni entera subjetividad, ni entera objetividad, sino una mezcla de ambas. Postula un "continuo" entre compromiso (conocimiento más centrado en el yo y con un alto grado de emocion- 


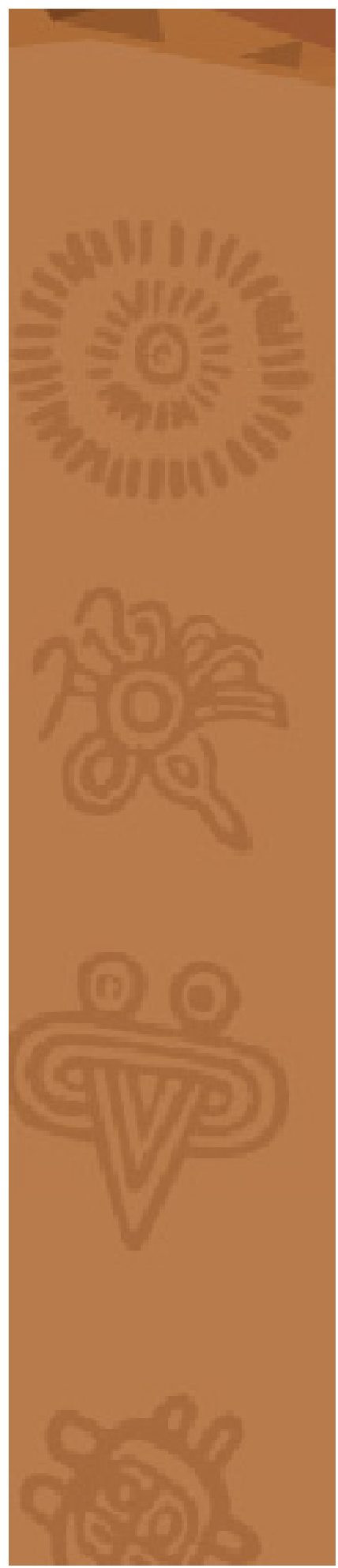

alidad) y distanciamiento (conocimiento más centrado en el objeto en sí y no tanto en el sujeto). El dilema consiste en precisar dicho continuo.

En efecto, no existe la posibilidad de acercarse al objeto de estudio sin que ello implique un trabajo analítico y reflexivo, considerando que toda descripción involucra una conceptualización de lo observado. Por ello, al decir de Willis (1985) “La organización teórica de la posición de partida debería ser delineada y conocida en cualquiera de las partes de la investigación" (1985, p.8). Es decir, es necesario que el investigador haga una confesión teórica, para abrirse a "escuchar y ver al otro" (1985, p.8), no tendría ningún sentido salir al campo a confirmar hipótesis, supuestos o teorías. Retomando la propuesta de Althabe y Hernández, para quienes

La implicación entra en escena en una forma particular: mediante las exclusiones de las cuales el antropólogo es objeto. El análisis de dicha dinámica (incorporación o expulsión del campo de interlocución) le permitirá comprender el modo de gestión del colectivo social. Las causas que autorizan la participación del investigador en situaciones de interacción o, al contrario, que justifican su expulsión, responden a una particular microfísica del poder. (2005, p. 80)

Tal como desarrolla Geertz (2006) la tarea de los antropólogos consiste en interpretar los significados que otorgan los sujetos a sus prácticas. Es decir, realizar interpretaciones de segundo y tercer grado, ordenando estructuras de significación, ejes claves, con un sentido social marcado. A la luz de la teoría construyen un texto ficcional, denominado por el autor como descripción densa.

De esta manera, el campo se presenta no como el mero lugar donde se construye el objeto y problemática de investigación, sino también donde el/la investigador/ra se evalúa así mismo como tal, siendo que es percibido/a por esos "otros". Ante esto, el campo se transforma en un continuo de reflexión que no se agota en el "estar allí", sino que exige un ejercicio constante, en el cual se organizan estrategias de acercamiento y construcción de conocimiento social.

\section{Experiencias y reflexiones sobre el trabajo de campo antropológico}

Se retoman algunas reflexiones antropológicas que analizan la experiencia del y en el trabajo de campo. Desde trabajos y reflexiones pioneras como las de Hermitte Esther ([1970], 2018a) exponiendo la técnica de la observación por medio de la participación, las particularidades de su implementación y los recaudos a tener en cuenta para lograr un conocimiento válido. "Aunque el antropólogo define en parte su rol, este es también en parte definido para él por la situación y la perspectiva de los estudiados." ([1970], 2018a, p. 94). También, Hebe Vessuri ([1973 ]2018) vinculaba críticamente la tradición británica malinowskiana con la realidad latinoamericana y la prospectiva de la transformación social. Sugería allí discutir "algunos aspectos de la observación participante" atendiendo a "la necesidad de una ciencia creadora, comprometida con el cambio necesario en las estructuras de nuestras sociedades latinoamericanas" (2018, p.289) 
Ángel Palerm ([1974], 2018a) quien insiste sobre la enseñanza del trabajo de campo en los primeros años de la Antropología, argumenta que "ni los métodos, ni las técnicas, ni los procedimientos analíticos de la etnología, pueden enseñarse, ni mucho menos aprenderse, fuera de las condiciones reales del trabajo de campo." ([1974], 2018a, p. 87) También Esteban Krotz ([1977], 2018a) profundiza sobre las situaciones que despierta la práctica del trabajo de campo, en la que la neutralidad valorativa con la problemática que se estudia no es posible, dado que el antropólogo/a se encuentra atravesado por las mismas estructuras y procesos sociales al estudiar en su misma sociedad. Concluye que "resulta imperativo intensificar el auto-análisis antropológico de la antropología (...) para mejorar el estudio de la realidad social y cultural en función de la transformación urgente." ([1977], 2018a: 141)

Por su parte, la antropóloga Fernández Álvarez, M (2010) en su artículo titulado Desafíos de la investigación etnográfica sobre procesos políticos "calientes", realiza un recorrido de su trabajo de investigación trabajadoras/es que habían iniciado recientemente el proceso de ocupación y gestión obrera de la producción de una empresa textil ubicada en la Ciudad de Buenos Aires.

El trabajo de campo siguió los cánones tradicionales de la investigación etnográfica que suponen un estar ahí cotidiano y prolongado, generando un modo de conocimiento que se basa en el establecimiento de relaciones personales. La antropología tiene una amplia tradición de reflexión crítica sobre su propia práctica que se ha convertido en un rasgo intrínseco al quehacer etnográfico. Desde esta tradición, el trabajo de campo supone no sólo observar sino participar de las situaciones sociales y sobre todo transformar la experiencia de investigación en un hecho etnográfico, es decir un dato construido. (2010, p. 82)

Su investigación tuvo como problemática las transformaciones en el mundo de trabajo y vida cotidiana, un estudio antropológico de los procesos de ocupación y recuperación de empresas. En el artículo mencionado reflexiona sobre su investigación, las relaciones que se establecen con los "otros" durante el trabajo de campo, analizando su "mirada implicada". Argumenta que dichos vínculos "nos involucran política, ética e incluso afectivamente y nos exigen tomas de posición, situaciones de tensión y negociación e incluso confrontación y padecimiento." (Fernández Alvarez: 2010, p. 88)

En este sentido considera que "el ejercicio de la antropología debería pensarse como un modo de participación que supone diálogo, intercambio y autorreflexión, cuyo compromiso se define siempre desde la investigación." (Fernández Alvarez: 2010, p. 86) Ella lo relaciona con la dificultad en el momento de escribir, cómo y cuánto escribir, qué datos ponderar, qué aspectos analizar y cómo aportar a estos procesos que estudia.

Las experiencias de Loic Wacquant (2006) y Philippe Bourgois (2015), expresan a las claras la producción antropológica en el involucramiento con los sujetos de investigación. Wacquant (2006) se introduce en el mundo del boxeo, 


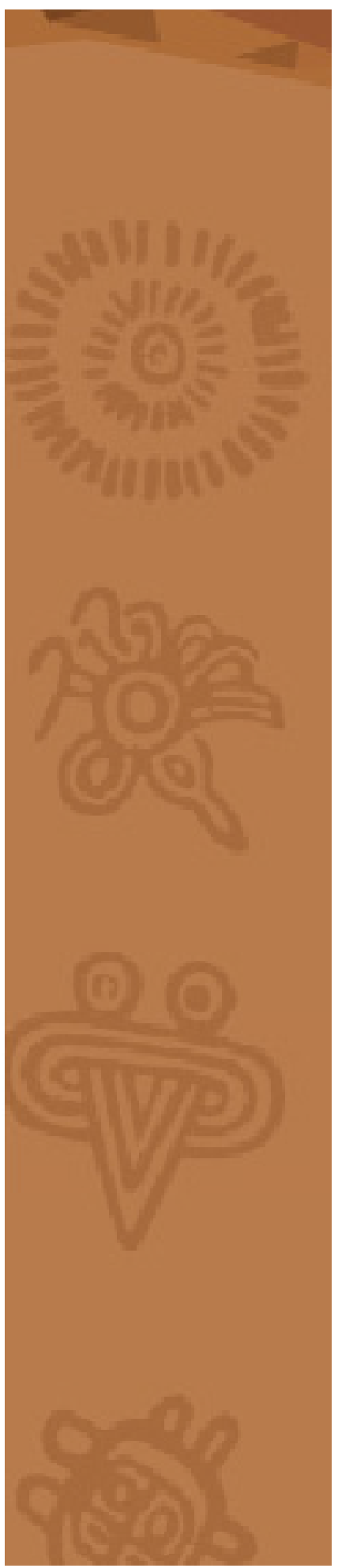

fue la necesidad de comprender y de dominar plenamente una experiencia transformadora que no había deseado ni anticipado, y que durante mucho tiempo permaneció confusa y oscura, lo que me impulsó a tematizar la necesidad de una sociología no sólo del cuerpo en sentido de objeto sino a partir del cuerpo como herramienta de investigación y vector de conocimiento $(2006$, p.16).

Bourgois (2015) se instala en el East Harlem (New York) junto a vendedores de crack: "¿Cómo esperar que una persona experta en asaltar ancianos suministre información precisa sobre sus estrategias de generación de ingresos?" $(2015$, p. 43) Cito en extenso:

Solamente tras establecer lazos de confianza, proceso que requiere mucho tiempo, es posible hacer preguntas incisivas con respecto a temas personales y esperar respuestas serias y reflexivas. Por lo general, los etnógrafos viven en las comunidades que estudian y cultivan vínculos estrechos de larga duración con las personas que describen. Para reunir "datos precisos", los etnógrafos violan los cánones de la investigación positivista. Nos involucramos de manera íntima con las personas que estudiamos (2015, p. 43).

A. Stagnaro (2006) analiza la noción de implicancia para reflexionar sobre situaciones durante su trabajo de campo en una investigación en empresas biotecnológicas, donde analiza la implicación del antropólogo en el mundo social del cual pretende dar cuenta, en contraposición al antropólogo como sujeto externo y distante, como condición de una supuesta cientificidad. Considera que la implicancia es un recurso que posibilita la participación en la práctica de investigación, acompañado por una actitud reflexiva. Argumenta que la:"articulación de la implicación con la reflexividad, experimentada en un movimiento dialéctico, da lugar a un análisis más profundo, enriqueciendo y ahondando el despliegue de la una en la otra, expandiendo así el horizonte interpretativo." (Stagnaro:2006, pp. 92 - 93) En este sentido, la autora resalta que la implicancia subjetiva en las instancias etnográficas aportan a una mirada más agudizada y analítica de lo que se está investigando, mediando un esfuerzo reflexivo sobre lo que allí sucede, en otras palabras anteponer un distanciamiento como herramienta teórica metodológica.

\section{Reflexiones finales}

Se reconoce que la producción social de conocimiento se construye a partir de la relación e interacción de un sujeto (el investigador) con otros sujetos a los que se los intenta comprender. En el transcurso del trabajo de campo se vivencian experiencias, malestares, problematizando lo ético y poniendo en juego cuestiones afectivas (en tanto que afectan) del quehacer antropológico. Reflexionar sobre la práctica 
antropológica, sobre cómo debería ser, los aspectos éticos, el respeto que se les debe otorgar a las personas con las que se interactúa, pensar sus tiempos, los propios, resulta fundamental, debido a que:

Es en la Antropología donde necesariamente se establece un puente entre dos universos de significación, y tal puente o mediación se realiza con un mínimo de aparato institucional o de instrumentos de mediación. Vale decir, de manera artesanal y paciente, dependiendo esencialmente de humores, temperamentos, fobias. (Da Matta, 2007:230)

Se considera al objeto de las ciencias sociales como histórico, en un determinado tiempo/espacio en constante transformación, reconociendo a los actores sociales como poseedores de una conciencia histórica. En disonancia con los métodos de las ciencias naturales, el objeto en las ciencias sociales no se trata de algo aislado y de distinta naturaleza del sujeto investigador, sino que se torna en una relación de sujeto/sujeto, conformando identidades e ideologías en el proceso de conocimiento, el cual resulta complejo, contradictorio y dinámico. (Achilli, 2005)

De esta manera se problematizan las dicotomías cuantitativo/cualitativo, subjetivo/objetivo, las cuales acarrean la cuestión de la objetividad. Acordamos con De Souza Minayo (1997), quien retomando aportes del funcionalismo ("los imponderables de la vida real", Malinowski), de la fenomenología (las realidades sociales son construidas) y de la dialéctica marxista (realidad como una totalidad social), considera que la objetividad en las ciencias sociales es una tarea irrealizable, sin embargo la objetivación es posible. Objetivación que dependerá del instrumental teórico y estratégico adecuado en el proceso de investigación.

Resulta importante reflexionar sobre la construcción del conocimiento social, en el involucramiento con las personas con las que se interactúa para construirlo, lo que genera algunas contradicciones. Según Stagnaro (2006) la contradicción atribuida a la posición del antropólogo como actor y productor de conocimiento cuestiona seriamente tanto el recurso metodológico de la ruptura, la separación y la objetivación del sistema de conocimiento de los demás; o en su extremo opuesto de mimetismo total con la forma nativa de percepción y significado. En el contexto de la tensión que surge entre el rol que se le asigna en el mundo de los demás y la distancia contradictoria que debe defender y construir constantemente en el transcurso de su investigación, es "donde se produce el conocimiento desde el interior de los campos sociales, propia del saber antropológico." (2006, p.98) Para finalizar se retoman unas palabras de Martín Barbero "sólo investigamos de verdad lo que nos afecta, y afectar viene de afecto." (2004:22) Porque, en definitiva, se investiga lo que nos involucra y moviliza, lo que nos atraviesa subjetivamente más allá de lo académico. 


\section{Bibliografía}

ACHILLI, E (2005) Investigar en antropología social. Los desafíos de transmitir un oficio, Ed. Laborde, Rosario

ALTHABE, GÉRARD Y VALERIA HERNÁNDEZ (2005). “Implicación y Reflexividad en Antropología” En: Etnografías Globalizadas, Hernández, Valeria,Cecilia Hidalgo y Adriana Stagnaro, (comps.), Sociedad Argentina de Antropología, Buenos Aires, 71-99.

DA MATTA, R (2007) "El oficio del etnólogo o cómo tener Anthropological Blues", en Boivin, Rosato y Arribas (comps) Constructores de Otredad. Una introducción a la Antropología Social y Cultural, Antropofagia, Buenos Aires.

ELIAS, N. (1990) Compromiso y Distanciamiento. Ensayos de Sociología del Conocimiento. Editorial Península: Barcelona.

FERNÁNDEZ ÁLVAREZ, M (2010) en su artículo titulado Desafíos de la investigación etnográfica sobre procesos políticos “calientes". (con)textos. revista d'antropologia i investigació social, Número 4. Maig de 2010

GUBER, R. (2001) “La Etnografía. Método, campo y reflexividad”, Buenos Aires, Norma.

GUBER, R. (2004) “El Salvaje metropolitano” Editorial Legasa, Buenos Aires.

HERMITTE, E ([1970], 2018a) "La observación por medio de la participación”. En GUBER, R (2018a) (Coord) “Trabajo de campo en América Latina. Experiencias antropológicas regionales en etnografía” Editorial SB, Colección Paradigma Indiciario. Buenos Aires.

KROTZ, E. ([1977], 2018a) "El caminar antropológico: ensayo sobre el trabajo de campo y su enseñanza” . En GUBER, R (2018a) (Coord) “Trabajo de campo en América Latina. Experiencias antropológicas regionales en etnografía” Editorial SB, Colección Paradigma Indiciario. Buenos Aires.

MARTÍN BARBERO, J. (2004) Oficio de Cartógrafo. Travesías latinoamericanas de la comunicación en la cultura. FCE. Buenos Aires

MINAYO, M. C. S (1997) El desafío del conocimiento. Investigación cualitativa en salud. Lugar Editorial, Buenos Aires.

PALERM, A ([1974], 2018a) “Teoría Antropológica y trabajo de campo en la formación de antropólogos sociales y etnólogos en América Latina”. En GUBER, R (2018a) (Coord) “Trabajo de campo en América Latina. Experiencias antropológicas regionales en etnografía” Editorial SB, Colección Paradigma Indiciario. Buenos Aires. 
ROCKWELL, E (1987) Reflexiones sobre el proceso etnográfico. Departamento de Investigaciones educativas. Centro de Investigaciones y Estudios Avanzados del IPN, México.

ROCKWELL, E (2011) La experiencia etnográfica: historia y cultura en los procesos educativos, Paidós, Buenos Aires.

STAGNARO, ADRIANA A. (2006) De antropóloga externa a antropóloga local: Diferentes modos de implicación Cuadernos de Antropología Social, núm. 23, 2006, pp. 81-103 Universidad de Buenos Aires Buenos Aires, Argentina

VESSURI, HEBE (2002) “La observación participante en Tucumán 1972” GUBER, R (2018a) (Coord) "Trabajo de campo en América Latina. Experiencias antropológicas regionales en etnografía" Editorial $\mathrm{SB}$, Colección Paradigma Indiciario. Buenos Aires

WILLIS, P. (1985) “Notas sobre el método”. En: Cuadernos de Formación No2, Santiago de Chile

\section{María Cecilia Telleria}

Licenciada en Antropología (Universidad Nacional de Rosario, Argentina, 2018), maestranda en Estudios Culturales (Centro de Estudios Interdisciplinarios - UNR), integrante del Centro de Abordajes Interdisciplinarios de lo Sociocultural (CAISUNR), adscripta en la cátedra de Metodología y Técnicas de la Investigación orientación Sociocultural. 